\title{
RESEÑA \\ SALAVERNA: CRÓNICA DE UN DESPOJO
}

Humberto Márquez Covarrubias*

Documental: Salaverna

Dirección: Edin Alain Martínez

País: México

Año: 2013

Duración: $70 \mathrm{~min}$

\section{CUANDO LA GENTE ESTORBA}

$\mathrm{E}$ n México, al norte del estado de Zacatecas, en el municipio de Mazapil, desde 1985 opera la Minera Tayahua, filial del Grupo Frisco, propiedad del magnate rentista Carlos Slim. De la mina subterránea se extrae, principalmente, cobre y, en menor cantidad, plata y zinc. En 2013, la Secretaría del Medio Ambiente y Recursos Naturales (Semarnat) autorizó el proyecto para la explotación de cobre a tajo abierto en un área que abarca 300 hectáreas donde se excavará un enorme cráter de 40 hectáreas y 230 metros de profundidad. El plan de producción contempla la extracción diaria de 42 toneladas métricas de cobre catódico con una pureza de 99.9 por ciento, considerada de alto valor industrial. El método de lixiviación

* Docente-investigador de la Unidad Académica de Estudios del Desarrollo de la Universidad Autónoma de Zacatecas, México. 
requiere la aplicación indiscriminada de sustancias corrosivas y tóxicas: durante una década, cada año se utilizarán 97 mil toneladas de ácido sulfúrico, 850 toneladas de explosivos de nitrato de amonio (Tovex 700) y mil 200 metros cúbicos de queroseno (Valadez, 2013).

El obstáculo para el poderoso Grupo Frisco es que, disponiendo de los derechos mineros, no detentan los títulos de propiedad de las viviendas ocupadas por los habitantes de Salaverna, cuyo pecado es residir sobre el codiciado yacimiento. En buena medida los vecinos son ancianos y poseen títulos de propiedad agraria sobre las ambicionadas parcelas. Con el propósito de derruir el poblado y explotar el tajo a cielo abierto, la minera reubicó a la mayor parte de la población a una nueva unidad habitacional denominada Nueva Salaverna (Navarrete, 2012).

Esta es la breve historia de una comunidad dedicada al pastoreo, la agricultura y la minería que resiste el embate de una corporación extractivista apoyada por el gobierno para que se desaloje el poblado. El panorama es sórdido. Entre casas en ruinas persisten las humildes moradas de 35 familias que decidieron permanecer. La mina está ubicada a 15 kilómetros de la mina Peñasquito, la explotación de oro a cielo abierto más grande de América Latina, concesionada a la canadiense Goldcorp, donde también hierve la conflictividad social, pero esa es otra, la misma historia.

\section{NO CONOZCO GOBIERNO}

En Salaverna, documental de Edin Alain Martínez (2013), un grupo de habitantes protagoniza una resistencia pacífica ante la amenaza de desalojo emprendida por la Minera Tayahua con el apoyo del gobierno a fin de despoblar la zona, derruir los caseríos y abrir un gran boquete para remover y pulverizar la tierra, aplicar sustancias tóxicas y sustraer cobre.

En la Convención Minera de 2012 celebrada en Zacatecas, el gobernador de la entidad, el priista Miguel Alonso, se ufana de que Zacatecas, con «corazón de plata y rostro de cantera [...] [,] tiene rumbo económico 
para el turismo, la minería y la industria de autopartes». Como buen gestor ofrece todas las facilidades para que los industriales obtengan del subsuelo la materia prima sin hacer mención de los costos social y ambiental derivados de las operaciones extractivas. Por ese mérito los industriales del ramo le han otorgado el nombramiento de Gobernador Minero de México (NTR, 7 de marzo de 2012).

En el evangelio neoliberal, las corporaciones rentistas aparecen como redentoras de las comunidades. En la Convención, los mineros dicen no afectar a los pobladores ni al medio ambiente. Un conspicuo representante nacional de los ingenieros metalurgistas afirma: "Nunca llegamos y quitamos a nadie. Nunca jamás hemos quitado a nadie. En un negocio minero donde alguien pierde, no estamos». Y complementa: "La industria minera está remediando lugares. [...] La minería, después del Ejército, es la industria que más planta árboles, que más tiene programas y proyectos de remediación. [...] No existen más ambientalistas que nosotros. Cuando tú le enseñas a una comunidad el beneficio que puedes traer, el desarrollo sustentable, la educación, los niveles de vida, nadie se opone en su sano juicio».

En contraste, un habitante del poblado en resistencia, don Roberto de la Rosa, deambula taciturno por los parajes abandonados de la Salaverna despojada. Entonces se escucha un son declamado: "Si el gobierno es de los pobres, yo no he conocido gobierno». De viva voz, don Roberto reflexiona: "(A) Los gobiernos se les olvida que están puestos por el mismo pueblo y que los empleos que ellos tienen son dados por el mismo pueblo. Ellos se deben al pueblo, no a los capitalistas; no a gente a la que se le hincan, a la que ven como el rey extranjero». Y remata lacónico: «Esa gente ha estado jugando con nuestros intereses».

En otro corte, aparece una sucesión de titulares de la prensa local que ofrece una panorámica del conflicto: «Concesionado 35\% del territorio estatal», «Mineras viven paraíso fiscal», «Violan mineras normatividad laboral», «Muere de 50 años mayoría de los mineros», «Destruyó Frisco a Noria de Ángeles», "Slim pone en riesgo vida de mineros», «Mineras generan pueblos fantasma», "Hostiga Slim a la gente de Sa- 
laverna», "Varios intentos de desalojo en Salaverna», "Amenaza a habitantes del Antiguo Salaverna: cese de servicios como agua potable y electricidad; pretenden demoler la escuela y la iglesia»y «Miseria sobre oro y plata».

\section{LA VOZ DE LOS SIN VOZ}

Sin las grandes pretensiones estilísticas de la filmografía contemporánea, el documental cede la voz a los actores, las víctimas del despojo. En entrevistas a cuadro, los habitantes que se resisten al desahucio exponen con parsimonia sus justas razones. Arguyen que la minera los quiere expulsar desconociendo los derechos de posesión de una población que estuvo asentada mucho antes de que la empresa arribara al lugar. $Y$ aducen que con mentiras y engaños han procedido al desalojado. Según los testimonios, quienes primero abandonaron el sito eran personas que vivían en una casa que no era suya o en casas de la compañía minera; también quienes de hecho ya vivían en otros lugares, por ejemplo en la cabecera municipal de Mazapil o en la vecina ciudad de Saltillo, Coahuila.

Don Roberto advierte que hace dos años la empresa anunció que querían reubicarlos porque había peligro de hundimiento y decían estar muy preocupados por la integridad física de los habitantes. Pero los habitantes tenían claro que se trataba de un engaño, pues los emisarios tenían el interés de desterrarlos para permitir la explotación libre de la mina a tajo abierto. Los inspectores de protección civil habrían admitido que los hundimientos sólo podrían ocurrir si eran intencionales. Y remata: "Nosotros estamos a gusto aquí. La minera quiere despojarnos, como si fuéramos unos delincuentes».

Con fotografías en mano, Francisco Javier Contreras, también habitante del poblado, dice que un día se presentaron abogados y trabajadores de la empresa para destruir, con lujo de violencia, un inmueble que desde hacía 28 años estaba bajo su posesión. En el hecho relatado, uno de los abogados de esa comitiva tomó una barra y derribó una 
puerta; sacaron los objetos del interior y tumbaron la pared trasera. Pero los habitantes contuvieron la destrucción total.

Una señora de edad mayor ofrece su propio testimonio. Pese a su avanzada edad, sin mediar consentimiento y estando ella adentro, derribaron, sin más, su vivienda. La señora no había aceptado irse, pues entre otras razones no le habían asignado casa en el fraccionamiento, sólo a su hijo. Pero habría recibido amenazas y acusaciones, según las cuales al permanecer en su propia casa estaba ocupando un «terreno ajeno». Viviendo en la pobreza, se queja de que el gobierno no ha ofrecido ningún tipo de ayuda, como no sea desalojar.

Don Estanislao, otro de los habitantes, dice: «Somos gente de la tercera edad, la mayoría. Nos van a quitar el modus vivendi. El dinero que nos quiere dar la empresa no vale lo que tenemos».

De manera ilustrativa se menciona el caso de un poblador que, como el resto, había recibido el ofrecimiento de cambiarse a una de las pequeñas casas del fraccionamiento, pero cuando preguntó si a cambio recibiría apoyo para la manutención, pues el sobrevive de pastorear chivas, y como recibiera una tajante respuesta negativa, rehusó a cambiarse, pues sabía que la mudanza significa perder su modo de vida y de trabajo.

\section{LOCACIONES DEL DESAMPARO}

Pese a que no se consigna una fecha exacta de la fundación de Salaverna, en el filme se tiene la certeza de que los primeros pobladores llegaron a principios del siglo pasado para dedicarse al pastoreo y la agricultura, mucho antes que la minera. En la zona había veneros de agua y florecía la crianza de ganado menor. Pero las mineras fueron ocupando a la gente y envolvieron con su dinámica a la población: cuando las compañías se fueron, dejaron en el desamparo a los habitantes y propiciaron la emigración. Los parajes despoblados ofrecen estampas fílmicas fantasmagóricas. Aranzazú es el vivo ejemplo de un poblado que pasó de la bonanza al olvido; en ese sito ahora sólo viven 3 per- 
sonas. Cuando abrieron un túnel entre las comunidades de Salaverna y Providencia para fines de la producción minera se cortaron los mantos de agua y la sequía detonó la emigración. A la empresa le habría resultado gratuito el desalojo y la apropiación de las tierras para explotarlas libremente.

Las imágenes de Salaverna son las de una zona devastada y desolada. En las tomas panorámicas aparecen casas demolidas y camiones con carga de materiales que circulan incesantemente. Las casas habitadas muestran grietas. Por las calles empedradas no circulan personas. Las escuelas están abandonadas. Los habitantes resisten.

El poblado está horadado. Los pozos Robin, respiraderos de la mina, arrojan a la atmósfera gases tóxicos y un pertinaz zumbido que en conjunto producen malestares en los habitantes. El síntoma se expresa en un cuadro clínico de tos, estornudos y dolores de cabeza. La contaminación del aire colorea el paisaje en tonos grises.

Los signos de la devastación también se registran en las inmediaciones. A sólo tres kilómetros al norte de Salaverna se localiza Providencia, un poblado en ruinas donde prosperó la minería, pero con su declive cíclico, la comunidad fue desalojada por la minera Peñoles en 1962. El éxodo de los mineros se dispersó hacia distintos lugares, incluyendo Salaverna. Ahora Providencia, donde se encuentra el llamado Cañón de la Mula, es un pueblo fantasma, el residuo de una explotación minera.

\section{EDUCACIÓN FUGITIVA}

Una voz en off, grabada en la Convención Minera, dice: "El desarrollo que esta actividad lleva a sus comunidades, por más recónditas que sean... (sic)». La palabra desarrollo pretende, siempre, legitimar el extractivismo minero. Y continúa: "La minería moderna mexicana es toda una filosofía de vida [...] [que] conlleva educación y muy buenos niveles de vida, con gran sentido de servicio a las comunidades». 
El despojo territorial se acompaña del despojo de otros bienes comunes, como la educación pública. En consonancia con los afanes del desplazamiento poblacional, la Secretaría de Educación de Zacatecas (Seduzac) decidió cerrar las escuelas primaria y secundaria. Las familias en resistencia y sus hijos quedaron sin acceso a la educación pública, fueron despojados de un derecho elemental. Los estudiantes ofrecen su testimonio y se muestran tomas cuando caminan por las calles entre casas derruidas.

La educación pública abre otro espacio de conflictividad. Las instalaciones escolares construidas en el Nuevo Salaverna funcionan como otro señuelo: el requisito de admisión es tener el domicilio en dicho fraccionamiento. Como se documenta, en 2012 representantes de la minera Tayahua y una maestra tomaron mobiliario, equipo y útiles de la escuela Vicente Guerrero para trasladarlo a las nuevas instalaciones, pero la comunidad lo impidió y recuperó el material para resguardarlo en la escuela.

Para acudir a la primaria, los escolares excluidos tienen que trasladarse diariamente a la cabecera municipal de Mazapil, a 10 kilómetros. Una madre de familia con tres hijos debe tomar un taxi y pagar 50 pesos por vuelta y 20 pesos más para regresar. La aspiración de la familia es que los hijos estudien para que no trabajen en la mina o si lo hacen que no sean obreros sino ingenieros.

Una estudiante de la abandonada Telesecundaria González Bocanegra habría pasado al segundo año, pero es la única persona sentada en el salón. Echa de menos a sus compañeros y al maestro que ahora están en el Nuevo Salaverna. Otras dos niñas egresadas de la primaria acuden a la secundaria sin maestros.

\section{CONFINAMIENTO EN MICRO CASAS}

Para culminar el desalojo, Frisco construye el fraccionamiento Nuevo Salaverna a cinco kilómetros del poblado original para albergar a 90 familias. El 
fraccionamiento fue inaugurado por el gobernador Miguel Alonso y Alejandro Aboumrad, director de Frisco. Está dotado con micro casas, al estilo de los fraccionamientos de interés social; además dispone de escuela, iglesia y un aula digital de Telmex, otra empresas de Slim.

Para incentivar el poblamiento del fraccionamiento, la empresa amenazó con despedir a los trabajadores de la mina cuyos familiares se negaran a dejar sus viviendas. Los lugareños han denunciado que la empresa utilizaba a guardias privadas para amedrentar a los habitantes a fin de que aceptaran el cambio de domicilio.

Caravanas de funcionarios públicos, directivos y abogados de la minera visitan Salaverna con la intención de persuadir a los habitantes para que abandonen su comunidad y acepten instalarse en el Nuevo Salaverna. Pocos accedieron a dejar sus fincas de adobe y piedra para ocupar las pequeñas casas de interés social.

\section{EVACUEN, LA TIERRA SE HUNDE}

La empresa minera fue acusada públicamente de realizar detonaciones subterráneas nocturnas que cimbraron y afectaron las casas. Se registraron hundimientos de tierra de aproximadamente una hectárea. El gobierno se mostró indiferente. El secretario de gobierno, Francisco Escobedo, justificó los hundimientos diciendo que se debían a las lluvias y los escurrimientos subterráneos, además recurrió al argumento de la empresa de que los habitantes no pusieran en riesgos sus vida y abandonaran la comunidad.

Ante los llamados de auxilio provocados por los estruendos terrenales, personal de Protección Civil acudió a inspeccionar la zona. Testificaron el derrumbe de miles de toneladas que habían colapsado dentro de la mina en el nivel 9. El derrumbe emergió a la superficie con unos 30 metros de circunferencia y 6 u 8 metros de profundidad. Las indicaciones son las mismas: evacuar el pueblo. La situación de riesgo es alta, un colapso pondría en peligro a la población. Ante el abandono 
gubernamental, los derrumbes y daños estructurales en las casas, algunas familias se mudan.

Un personero de la empresa, abogado de la mina, se presenta y dice a los pobladores en resistencia: «si alguien se quiere cambiar ahorita, hay casas disponibles [...] Si ustedes dicen que no caben, que la casa está muy chica, tenemos que ser parejos con todos, no podemos darle a una persona una casa más grande que a otra, todas son del mismo tamaño $[. .$.$] Si alguien quiere cambiarse, firmamos contrato, se les hace$ la escritura y les ayudamos con la mudanza. Esa es la postura de la empresa».

\section{ANTE DERECHOS IGUALES, GANA LA FUERZA}

La resistencia al desalojo es por medios no violentos. Simplemente consiste en permanecer en sus casas. Pero la empresa acrecienta la presión: provoca detonaciones que dañan la estructura de las casas. Ante el riesgo de que sus casas se desplomen, los habitantes bloquean la entrada a la mina. Entonces el abogado de la empresa y don Estanislao escenifican el siguiente diálogo:

—Están cometiendo un delito, ustedes lo saben —dice el abogado.

- Métanme al bote - contesta don Estanislao.

-No, yo no lo voy a meter al bote.

- No estamos cometiendo un delito. Tenemos un derecho, un derecho humano.

- Todos tenemos derechos. Ustedes tienen derecho, la empresa tiene derecho.

- Nadie es culpable hasta que se demuestre lo contrario.

- Igual la empresa. La empresa no es culpable, hasta que se le demuestre. Si usted dice que la empresa es culpable, demuéstrelo.

Es sabido que ante derechos iguales, gana la fuerza. Del lado de la empresa está el gobierno y la fuerza pública, del lado de los habitantes está su propio testimonio. 
No hay acuerdo. Estanislao muestra un plano y dice que el polígono está en litigio. Los abogados de la minera y de la comunidad acuerdan reunirse después, pero el representante de la mina no asiste.

La empresa no da esperanzas de negociación, sólo quieren reubicar a la gente. Se ostentan como dueños del terreno donde habita la gente, sin serlo. Hay expedientes en Secretaría de la Reforma Agraria. La empresa quiere despojarlos y hacer sus explotaciones. Los pozos Robin ya están dentro del poblado. Están detonando dinamita para cimbrar las casas. No negocian con los afectados, sino con el gobierno.

Al lugar han acudido diputados, funcionarios públicos de dependencias como reforma agraria y educación pública, hasta el cura. Después que se pidió la intervención de la presidencia de la república, 6 meses después ofrecieron enviar una comisión. En la práctica, el derecho de petición brilla por su ausencia, al igual que el seguimiento a las necesidades de la gente.

\section{VOZ EN EL DESIERTO}

Don Roberto reflexiona:

Quieren más riqueza pisoteando los derechos de los demás. Todos están en contra de nosotros. No estoy en contra de la generación de empleos, estoy en contra de que no se trate con dignidad a los pueblos y que los quieran sacar sin ser beneficiados, y del daño tan grande que se le está haciendo al sistema ecológico. Será un desierto, pero para mi es el paraíso, que ya se nos secó por falta de agua.

El documental cierra con las siguientes notas informativas:

A lo largo de 2012, la comunidad de Salaverna presentó reclamos a las autoridades del gobierno de Zacatecas, sin obtener ningún tipo de apoyo. El bloqueo por parte de los pobladores de Salaverna se suspende por amenazas de la po- 
licía municipal de usar la fuerza para liberar la entradas a la mina. La mina despide a todos aquellos empleados que participan en los bloqueos en apoyo a la comunidad. Persiste la posibilidad de un desalojo violento a los habitantes de Salaverna.

La empresa y el gobierno habrían desalojado a 150 familias. Con el paso del tiempo, 38 familias se resistían, después quedaron, 18 familias, en última instancia sólo quedan 12 familias que se niegan a salir de sus hogares.

\section{REFERENCIAS}

Martínez, Edin Alain (2013), Salaverna, documental, 70 minutos, México.

Navarrete, Carlos (2012), «Resistencia de gente de Salaverna podría frustrar proyecto minero: Grupo Frisco», La Jornada Zacatecas, 24 de octubre de 2012, p. 6 .

NTR (7 de marzo de 2012), «Recibe Miguel Alonso reconocimiento Gobernador Minero de México», NTR, en http://ntrzacatecas.com/2012/03/07/recibemiguel-alonso-reconocimiento-gobernador-minero-de-mexico/.

Valadez, Alfredo (2013), «Autoriza la Semarnat explotar cobre a cielo abierto en Zacatecas», La Jornada, 27 de diciembre de 2013, p. 27. 